\title{
Host suitability, respiration rate and the outcome of larval competition in strains of the cowpea weevil, Callosobruchus maculatus
}

\author{
RAUL NARCISO C. GUEDES*, ROBERT H. SMITH and NELSA \\ MARIA P. GUEDES \\ Department of Biology, University of Leicester, U.K. and *Departamento de Biologia Animal, Universidade Federal de \\ Viçosa, Brazil
}

\begin{abstract}
Variation between strains of Callosobruchus maculatus in several lifehistory traits is well known. Differences in functional anatomy of egg pores and larval respiration rates have also been reported in strains from Brazil and Yemen. The response of five strains of $C$. maculatus to seeds of two host species, cowpea (Vigna unguiculata) and mung bean (Vigna radiata), was measured along with the larval respiration rates of the same strains on both hosts. There was significant variability of response to the two hosts. Strains with higher larval respiration rate ( $\mu \mathrm{L} \mathrm{O}_{2} /$ insect/day) showed higher seed consumption, which significantly affected adult emergence per seed on both hosts. This finding provides support for the hypothesis that differential feeding rate is an important mechanistic component of the larval competition outcome observed in strains of $C$. maculatus.
\end{abstract}

Key words. Bruchidae, Coleoptera, competition, legume seed beetles, oxygen uptake, Vigna radiata, Vigna unguiculata.

\section{Introduction}

The discontinuous nature of the stored seed environment imposes unusual problems for seed parasites, such as bruchid beetles. The cowpea weevil, Callosobruchus maculatus (F.) (Coleoptera: Bruchidae), is one such species with a west African origin, from where it spread throughout the tropical and subtropical world as a pest of seed legumes of worldwide importance (Southgate, 1978). Grain-storage units probably accentuate seasonal population cycles leading to bottlenecks where small numbers of individuals establish new populations, which quickly develop from them (Tanaka, 1990; Tran \& Credland, 1995; Guedes etal., 1997). This process produces inbreeding that, in successive phases, may purge deleterious genes from the genome, favouring further inbreeding in these populations (Tanaka, 1990; Tran \& Credland, 1995). Inbreeding

Correspondence: Dr Raul Narciso C. Guedes, Departamento de Biologia Animal, Universidade Federal de Viçosa, Viçosa, MG 36571-000, Brazil. Tel.: +55 333899 2006; fax: +55 333899 2537; e-mail: guedes@ufv.br frequently reduces vigour and fitness but it may lead to the evolution of interstrain differences in some granivorous species, such as C. maculatus (Tran \& Credland, 1995).

Callosobruchus maculatus is a semelparous species with a relatively simple life-history favouring its use as a model organism in population-biology studies. Females of this species lay eggs on the surface of various seed legumes, such as cowpeas (Vigna unguiculata) and mung beans ( V. radiata) (Southgate, 1979). Newly-emerged larvae burrow into and feed on a single seed until pupation and their emergence as adults that do not require further feeding (Mitchell, 1975). Therefore, the resources acquired during larval development, which are heavily influenced by the host seed, determine their reproductive potential, longevity and growth (Credland etal., 1986; Wasserman, 1986; Møller et al., 1989; Kawecki, 1995; Tatar \& Carey, 1995; Kawecki, 1997; Shade et al., 1999; Fox \& Czesak, 2000). In addition, because several eggs may be laid on a single legume seed where the larvae remain throughout their development, larval competition may be fierce and may also be influenced by the host seed species (Bellows, 1982).

There is wide variation in biological traits among geographically distinct strains of C. maculatus (Dick \& Credland 
1984; Credland, 1986; Dick \& Credland 1986; Credland \& Dick, 1987; Messina, 1989; Messina et al., 1991; Berg \& Mitchell, 1993; Chiu \& Messina, 1994; Savalli et al., 2000). Expression of this variation is likely to be influenced by the host seed and may help toward understanding the local evolution of these strains and how they relate to their distinctive larval competition strategies, which range from the scramble to the contest type (Nicholson, 1954; Dick \& Credland, 1984; Smith \& Lessells, 1985; Smith, 1990; Toquenaga, 1990, 1993; Colegrave, 1994; Horng, 1997; Lale \& Vidal, 2001; Takano et al., 2001).

An important issue is the distinction between the behavioural process of larval competition and the population outcome. The process is a consequence of intrinsically disruptive selection on larval competition strategies, whereas the outcome also depends on how much resource is required for development in relation to what is available within a patch of resource (seed) (Smith \& Lessells, 1985). Because high seed consumption and larval respiration rate have been associated with the Yemen strain (Credland \& Dick, 1987; Daniel \& Smith, 1994), which was described as approaching a contest-type of larval competition outcome (Credland etal., 1986), it was hypothesized that seed consumption and respiration would affect adult emergence and, consequently, the competition outcome assessed here as the number of adults emerged per seed. This would occur because higher larval respiration rates would be associated with high seed consumption leading to increasing interactions and mortality of larvae within a single seed. Limiting the number of adults emerged per seed might give the appearance of a contest-type of outcome, even if there was no direct behavioural interference.

The reported differences in larval respiration rate and per capita consumption of legume seeds in strains from Brazil and Yemen of C. maculatus (Credland \& Dick, 1987; Smith, 1990; Daniel \& Smith, 1994) may be of particular relevance for the larval competition outcome in strains of C. maculatus, with important applied consequences. Therefore, the objectives of the present investigation were to assess the overall response of different strains of $C$. maculatus when subjected to seeds of two different host species and to investigate how this response relates to the outcome of larval competition. Such variability of response is expected, but the consequences are uncertain. Larval respiration rate is related to resource use and may lead to a contest-type of outcome at high densities, regardless of the host seed.

\section{Materials and methods}

\section{Insect populations}

Five geographically distinct strains of $C$. maculatus from Brazil, India, Nigeria, Uganda and Yemen were used. The strain from Brazil was originally collected from cowpeas in Campinas, Brazil, in 1975, whereas the Nigeria strain was collected in Ibadan, during 1981, and was maintained on cowpeas at the International Institute of Tropical Agriculture (Ibadan, Nigeria); the Uganda strain was collected in
Kawanda, Uganda, in 1982; and the Yemen strain was collected from lentils in 1976, in Damar, Yemen Arab Republic. All of these four strains used were derived from stock cultures maintained at the U.K. National Resources Institute (formerly the Tropical Stored Products Centre). The India strain was originally collected from mung beans (Vigna radiata) and blackgram (Vigna mungo), during 1979, in Tirunelveli, South India and it was derived from stock cultures maintained at the Department of Biology, Utah State University, U.S.A. This strain is known in the literature as 'South India' and is recognized as sharing a contest process of larval competition, as well as a contest-like outcome (Mitchell \& Thanthianga, 1990). All of the strains, except the Indian strain, have been maintained on cowpea for several years at the University of Leicester. The India strain has been maintained on mung bean, but new lines were established in cowpea for three generations before use in this investigation. All cultures were maintained in an environmentally controlled room, where the experiments were also carried out, at $30 \pm 2{ }^{\circ} \mathrm{C}, 70 \pm 10 \%$ relative humidity and a photoperiod of LD $12: 12 \mathrm{~h}$.

\section{Studies of developmental response on two hosts}

Five grams of each host seed, cowpea (approximately 23 seeds) or mung bean (approximately 72 seeds), were weighed into $120 \mathrm{~mL}$ glass jars that had the upper part of their inner walls coated with fluon (AG Fluoropolymers, U.K.) to prevent insect escape. Five virgin adults of C. maculatus of the same strain (three females and two males), aged 0-24-h old, were introduced in each jar, which was covered by a perforated lid with a fine mesh metal screen fitted into it to prevent insect escape and allow maximum gas exchange. Oigiangbe \& Onigbinde (1996) have previously provided a description of this general method. The total number of eggs laid per seed and the percentage of hatched eggs were recorded after 15 days. After 30 days, the number of adults emerged and the seed weight were recorded. The emerged adults were sexed using elytral patterns (Southgate etal., 1957). The percentage of adult emergence was calculated from the number of hatched eggs. Six replicates were used for each strain during experiments with either host seeds. Each replicate was derived from a different line of insects of each strain individually maintained in $500-\mathrm{mL}$ jars at the laboratory.

\section{Respirometry study}

Oxygen uptake was measured in a Gilson Differential Respirometer (Gilson, 1963) using methods adapted from Daniel \& Smith (1994). A series of $13 \mathrm{~mL}$ flasks was used for each measurement, each flask containing 10 seeds with one newly laid egg $(<12 \mathrm{~h})$ each. A small filter paper wick with $0.20 \mathrm{~mL}$ alkali solution $(10 \% \mathrm{KOH})$ was placed in the centre of the flask for $\mathrm{CO}_{2}$ absorption. Thus, changes in volume of gas represented oxygen uptake, which was read by daily manometric adjustments with a micrometer scale. 
Readings were taken every $24 \mathrm{~h}$ over 7 days and daily barometric pressure readings were used to convert the respirometer volume changes to standard temperature and pressure conditions (Daniel \& Smith, 1994). Six replicates were used for each strain on either host seed, allowing the assessment of 60 eggs for each insect strain in each host species.

\section{Statistical analysis}

The variables estimated for the experiments of developmental response of strains of $C$. maculatus on each host were subjected to canonical variate analysis (CVA) using the procedure PROC CANDISC from SAS (SAS Institute, 1989), with the DISTANCE statement, and also to univariate analysis of variance and Fisher's least significant difference (LSD) test, when appropriate. The significance of the separation between strains of $C$. maculatus, indicated by the ordination through CVA, was determined by the pairwise comparison of the strains using the approximated $F$-test $(P<0.05)$ and the Mahalanobis distances between the respective class mean canonical variates. These distances were based on the pooled within-class covariance matrix of the treatments. The respirometry data from the third measurement on were subjected to repeated measures (multivariate) analysis of variance for each host species. These analyses were carried out using the procedure PROC ANOVA with the PROFILE statement (SAS Institute, 1989), following guidelines provided by von Ende (1993). Regression analysis between number of adult insects emerged per seed and total seed weight loss (\%) were carried out to assess the influence of seed consumption in the outcome of larval competition, estimated here as the average number of adults emerged per seed. This analysis was carried out using the procedure PROC REG from SAS (SAS Institute, 1989). Five variables [percentage of eggs hatched, number of eggs laid per seed, number of adults emerged per seed, grain consumption ( $\mathrm{mg}$ ) per adult emerged and larval respiration rate] had to be transformed to stabilize variance and to satisfy normality assumptions (PROC UNIVARIATE; SAS Institute, 1989). The first variable was transformed to arcsine $(x(\%) / 100)$, the last one was transformed to $\log _{10}(x+1)$ and the others were transformed to $\log _{10}(x)$.

\section{Results}

\section{Overall strain response}

The average values $( \pm$ SE) of each variable estimated in the experiments on both hosts are presented in Table 1. CVA analysis for cowpea indicated significant overall differences among strains (Wilks' lambda $=0.0087 ; F=8.56$, d.f. $=24,71 ; P<0.0001)$. This ordination analysis resulted in two significant canonical axes $(P<0.05)$, which were responsible for $84.4 \%$ and $14.3 \%$ of the total variance explained $(98.7 \%)$ in the data (Table 2). The traits with the highest standardized canonical coefficients (pooled withinclass; absolute values), and therefore contributing the most to the divergence between strains reared on cowpea, were total seed loss and number of eggs laid and adults emerged per seed, on the first axis and with opposing contributions, and number of adults emerged per seed and number of eggs laid per seed, on the second axis, and again with opposing contributions (Table 2).

CVA analysis for mung bean also indicated significant overall differences among strains (Wilks' lambda $=0.0063$; $F=5.43 ; \quad$ d.f. $=24,71 ; \quad P<0.0001)$, but the ordination resulted in three significant axes $(P<0.05)$ accounting for $54.5 \%, 32.6 \%$ and $8.7 \%$ of the total variance explained $(95.8 \%)$ (Table 2). The traits with the highest contribution for strain divergence on mung bean were different from the CVA analysis for cowpea. Number of eggs laid per seed and total seed loss were the main variables contributing to the first axis showing opposite contributions, with number of eggs and adults per seed as the main variables for the second axis, both showing positive contributions, and total seed loss and number of adults emerged per seed were the main ones for the third axis, showing opposite contributions (Table 2).

The ordination diagrams derived from the CVA analyses were plotted with just the two main canonical axes of each variable, which explain at least $87 \%$ of the total variance of each analysis (Fig. 1). The strains of $C$. maculatus from Brazil, Nigeria and Uganda were indistinguishable when reared on cowpea, forming a distinct cluster apart from the strains of India and Yemen, which were also significantly different from each other (Fig. 1a). By contrast, a cluster with the strains of Nigeria and Uganda was observed on mung bean showing significant divergence from the others (Fig. 1b).

\section{Larval respiration rates}

Three general hypotheses were addressed in each repeated measures (multivariate) analysis of variance: 'parallelism', 'flatness' and 'levels' (von Ende, 1993). In the present case, the parallelism was tested based on the significance of the Time-Strain interaction. If the interaction was not significant, as in the determinations on cowpea but not on mung bean (Tables 3 and 4), the slopes of the Strain effect through time were parallel (Fig. 2a,b). Again, the differences observed between these results indicated plasticity of strain responses in different hosts. Flatness was tested through the significance of the Time effect, because the Strain effect will not vary with time if the Time effect were not significant, unlike what happened in both instances reported here (Tables 3 and 4). By contrast, the test of level effect is a test of the Strain main effect, which was significant in both analyses. If the Time-Strain interaction was significant, as observed in mung bean, the tests of flatness and levels were of little importance.

The larval respiration rates on cowpea began to differ after the fourth day of hatching with the Yemen strain showing nearly $30 \%$ higher $\mathrm{O}_{2}$ uptake than the strain from Brazil at the end of the assay. The strains from India, Nigeria and Uganda showed intermediate respiration 


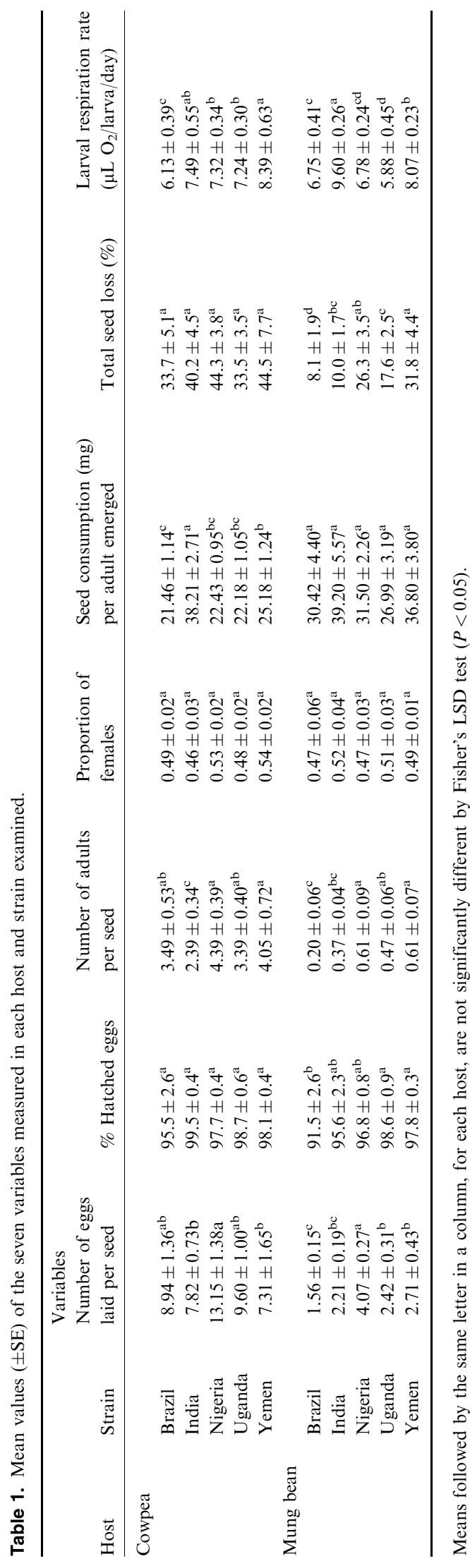

rates with the first showing a trend of surpassing the other two with further development (Fig. 2a). Larval respiration rates on mung bean showed a different pattern through time with the India strain showing higher levels subsequent to the early determinations, followed by the Yemen strain (Fig. 2b). The other strains showed lower larval respiration rates (up to $41 \%$ less than the India strain), with the Uganda strain showing the lowest values.

\section{Association between respiration, consumption and emergence}

The number of adult insects emerged per seed varied among strains reared on the same seed species, ranging from 0.20 to 0.61 adults emerged per mung bean and from 2.39 to 4.39 adults per cowpea (Table 1 ). As larvae of $C$. maculatus did not leave the seed from where the egg was laid, but developed on the substrate selected by their mother, the number of adults emerging per seed was the outcome of the initial number of eggs laid, the prevailing larval competition strategy and also the amount of resource required for successful development.

The difference in larval respiration rates increased with time (Fig. 2) and led to significant differences between strains at the end of the experiment in each host species, cowpea (d.f.error $=25 ; F=5.46 ; P=0.003$ ) and mung bean (d.f.error $=25 ; F=18.17 ; P<0.0001)$ (Table 1$)$. The India and Yemen strains of $C$. maculatus showed the highest larval respiration rates followed by the Nigeria strain. The Brazil and Uganda strains showed the lowest larval respiration rates and also the lowest seed consumption, measured here as total seed loss (\%; total seed consumption by all the larvae inside the seed) (significantly different for cowpea; d.f.error $=25 ; F=9.18 ; P<0.0001)$ and per capita consumption (significantly different for mung bean; d.f.error $=25$; $F=20.44 ; P<0.0001)$. In addition, seed consumption significantly affected the density of adults emerging per seed of both hosts, cowpea and mung bean (Figs 3 and 4).

\section{Discussion}

The distinct composition of the main canonical axes on both CVA analyses, for cowpea and mung bean, is an indication of the plasticity of these insect strains when exposed to different hosts. Smaller numbers of eggs were laid per seed on mung bean than cowpea, suggesting stronger competition within the second host despite its larger size. The smaller number of eggs laid and adults emerged per seed of mung bean indicated its unsuitability to C. maculatus, particularly the Brazil strain. Furthermore, three of the five strains studied (the American one from Brazil and the African strains from Nigeria and Uganda) were indistinguishable when reared on cowpea, but not on mung bean, probably reflecting their relative better adaptation to the first host, which they are more likely to encounter in their country of origin, unlike the India and Yemen strains (Credland etal., 1986; Mitchell \& Thanthianga, 
Table 2. Significant canonical axes $(P<0.05)$ and their standardized canonical coefficients (pooled within-class) of biological traits of five strains of Callosobruchus maculatus reared in two different hosts and subjected to canonical variate analysis.

\begin{tabular}{|c|c|c|c|c|c|}
\hline \multirow[b]{3}{*}{ Variables } & \multicolumn{5}{|c|}{ Canonical axes } \\
\hline & \multicolumn{2}{|l|}{ Cow pea } & \multicolumn{3}{|l|}{ Mung bean } \\
\hline & 1 & 2 & 1 & 2 & 3 \\
\hline Number of eggs laid per seed & -4.27 & -1.46 & -1.47 & 2.06 & -0.47 \\
\hline Percent of eggs hatched & -0.05 & -0.74 & -0.59 & 0.16 & -0.25 \\
\hline Number of adults emerged per seed & -1.11 & 1.48 & 0.74 & 1.95 & -1.37 \\
\hline Proportion of females & 0.24 & 0.43 & 0.40 & 0.72 & -0.38 \\
\hline Seed consumption (mg) per adult emerged & 0.45 & -0.25 & 0.96 & 1.08 & -0.99 \\
\hline Total seed loss $(\%)$ & 5.23 & 0.31 & 1.56 & -1.68 & 1.54 \\
\hline$F$ & 8.56 & 3.38 & 5.43 & 4.17 & 2.60 \\
\hline d.f. (numerator, denominator) & $24,71.0$ & $15,58.4$ & $24,71.0$ & $15,58.4$ & $8,44.0$ \\
\hline$P$ & $<0.0001$ & 0.0004 & $<0.0001$ & $<0.0001$ & 0.02 \\
\hline Squared canonical correlation & 0.84 & 0.14 & 0.55 & 0.33 & 0.09 \\
\hline
\end{tabular}
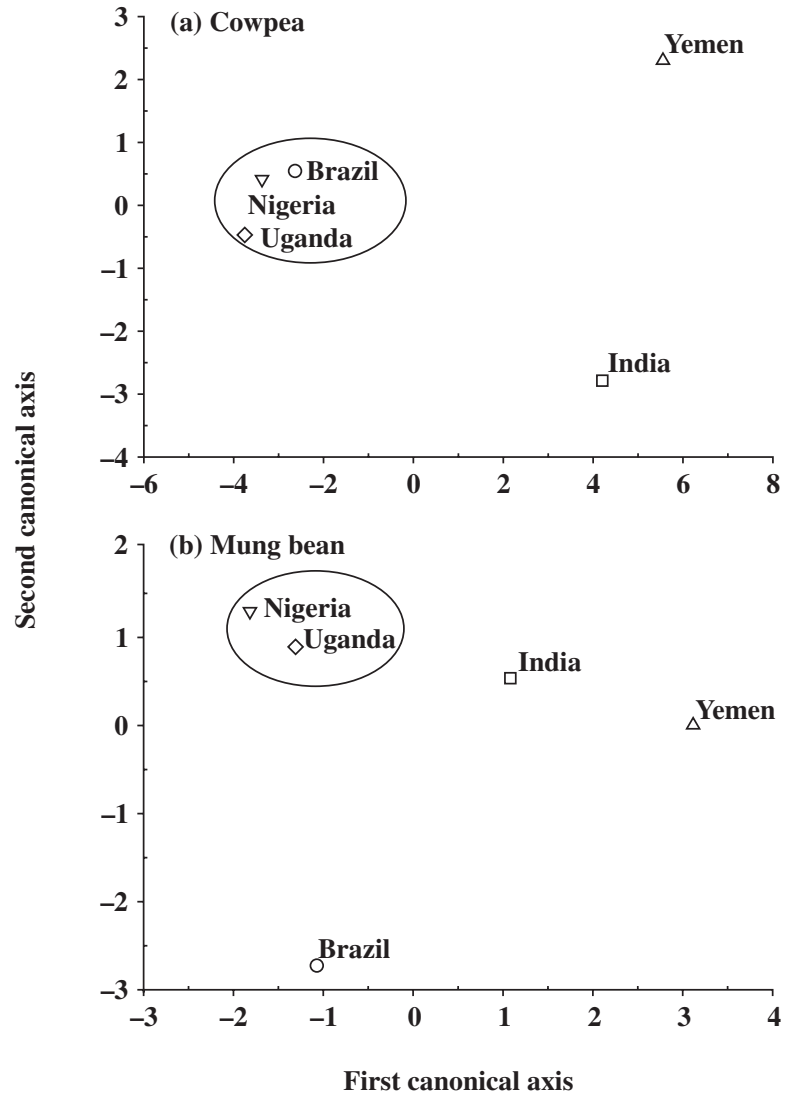

Fig. 1. Ordination (CVA) diagram showing the discrimination of the five strains of Callosobruchus maculatus reared on cowpea (a) and mung bean (b), based on the biological traits shown on Table 1 . The symbols are centroids of treatments and represent the class mean canonical variates. Large circles indicate clusters of treatments that were not significantly different by the approximated $F$-test $(P<0.05)$, based on the Mahalanobis distance $\left(D^{2}\right)$ between class means.
1990; Smith, 1990). These results reinforce the contention that local adaptation aided by periodic inbreeding is a major force driving the evolution of geographically distinct strains of C. maculatus (Tran \& Credland, 1995).

Phenotypic plasticity was inferred in the present study by the variation expressed for the traits investigated when the same strains were exposed to two different hosts. Such plasticity has value because it can affect natural selection on phenotypes and the genetic response to selection, as already demonstrated in C. maculatus (Smith \& Lessells, 1985; Møller etal., 1989; Smith, 1991; Kawecki, 1995, 1997). The patterns of plasticity observed here and the likely periodic inbreeding on this species suggest the possibility of adaptation of strains of $C$. maculatus to different hosts, subjected to the constraints of life-history trade-offs imposed by the novel host (Møller et al., 1989; Smith, 1991), and may prove useful in identifying the biotypes more likely to be serious threats in a particular environment, as recently suggested by Nylin (2001).

The Yemen strain of $C$. maculatus has been reported as showing high larval respiration rate, low conversion efficiency (i.e. insect biomass produced in relation to seed biomass consumed) and a nearly complete contest-type of competition outcome compared to the Brazil strain

Table 3. Multivariate analyses of variance with repeated measurements on larval respiration rates ( $\mu \mathrm{L} \mathrm{O}^{2} /$ larva/day) of five strains of Callosobruchus maculatus reared on cowpea and mung bean (between subjects).

\begin{tabular}{llrc}
\hline Sources of variation & $F$ & d.f. & $P$ \\
\hline Cowpea & & & \\
$\quad$ Strain & 2.83 & 4 & 0.04 \\
Error & & 25 & \\
Mung bean & & $<0.0001$ \\
Strain & 27.81 & 4 & \\
Error & & 25 & \\
\hline
\end{tabular}


Table 4. Multivariate analyses of variance with repeated measurements on larval respiration rates ( $\mu \mathrm{L} \mathrm{O} \mathrm{O}^{2} /$ larva/day) of five strains of Callosobruchus maculatus reared on cowpea and mung bean (within subjects).

\begin{tabular}{|c|c|c|c|c|c|}
\hline Sources of variation & Wilks' lambda & $F$ & d.f.numerator & d.f.denominator & $P$ \\
\hline \multicolumn{6}{|l|}{ Cowpea } \\
\hline Time & 0.0119 & 635.00 & 3 & 23 & $<0.0001$ \\
\hline Time $\times$ Strain & 0.5127 & 1.46 & 12 & 61.144 & 0.1632 \\
\hline \multicolumn{6}{|l|}{ Mung bean } \\
\hline Time & 0.0091 & 837.49 & 3 & 23 & $<0.0001$ \\
\hline Time $\times$ Strain & 0.0503 & 10.67 & 12 & 61.144 & $<0.0001$ \\
\hline
\end{tabular}

(Credland \& Dick, 1987; Smith, 1990; Daniel \& Smith, 1994). The functional anatomy of the egg pore on the Yemen strain, which is funnel-shaped, externally widening to a diameter twice its length, seems to allow a two- to three-fold increase in gas conductance and, consequently, allows higher oxygen uptake (Daniel \& Smith, 1994). Such

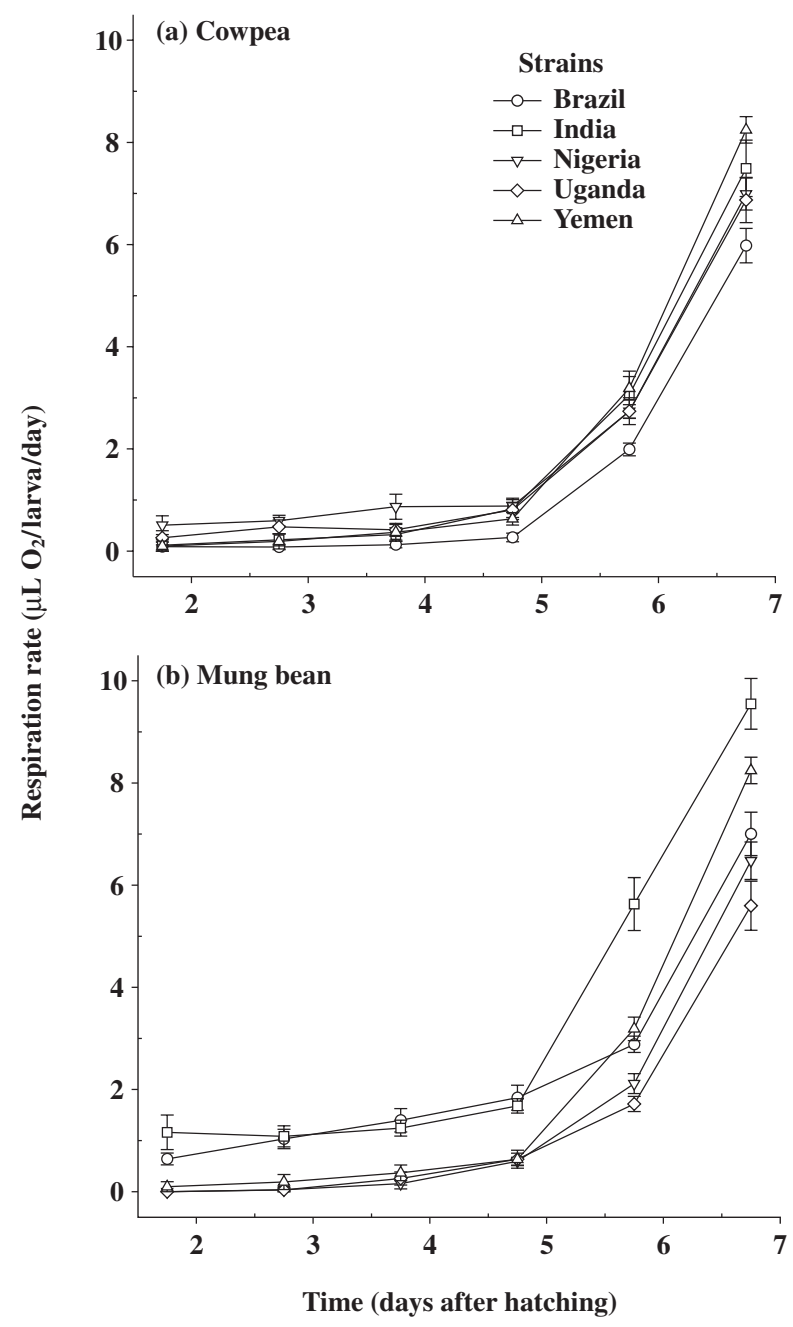

Fig. 2. Variation of larval respiration rate of five strains of Callosobruchus maculatus reared on cowpea (a) and mung bean (b). Symbols represent the average results of six replicates and the vertical bars indicate the standard errors of the means. peculiarity has its practical implications because this modified egg anatomy makes seed treatment with oils more efficient against this strain (Daniel \& Smith, 1994), but may also enable the larvae to cope better with detoxification of seed toxins (Smith, 1990) and even insecticides, although this remains to be tested.

Yemen insects emerge larger and consume more seed, which led to the suggestion that they are more likely to encounter other larvae within a seed than insects from other strains, resulting in larval competition resembling the extreme contest-type observed on the India strain (Smith, 1990; Toquenaga, 1993; Horng, 1997; Takano et al., 2001). Therefore, if the relationship between larval respiration rate and seed consumption holds for other strains, and is correlated with adult emergence per seed, this relationship may be able to provide a convincing mechanistic explanation for the contest-like outcome in some strains of $C$. maculatus, as was hypothesized here.

The differences in larval respiration rate observed appear to provide support for the hypothesis stated above. However, the larval respiration rates obtained for the Yemen strain in this study were not as high as those reported by Daniel \& Smith (1994) compared to the Brazil strain. In addition, the numbers of Yemen adults emerged per cowpea

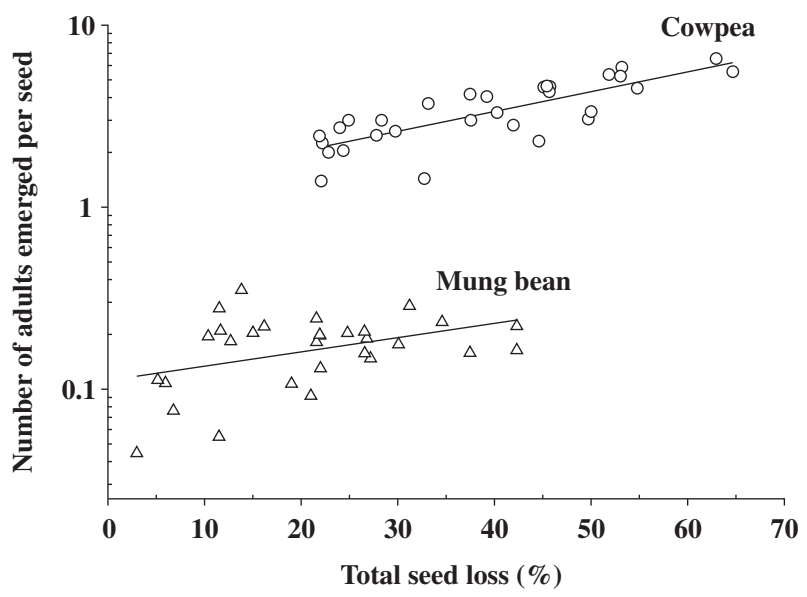

Fig. 3. Effect of total seed loss $(\%)$ in the number of adults emerged per seed of five strains of Callosobruchus maculatus reared on cowpea [open circle; $\log (y)=0.09+0.01 x$; d.f.error $=28$; $\left.F=47.75 ; P=0.001 ; r^{2}=0.63\right]$ and mung bean [open triangle; $\log (y)=-0.95+0.008 x ;$ d.f. .rror $\left.=28 ; F=5.62 ; P=0.02 ; r^{2}=0.17\right)$. 


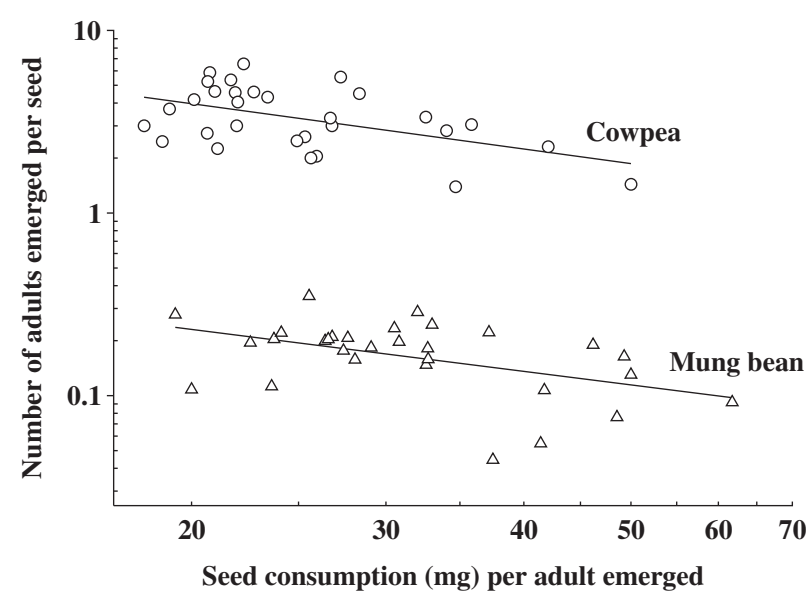

Fig. 4. Effect of grain consumption (mg) per emerged adult in the number of adults emerged per seed of five strains of Callosobruchus maculatus reared on cowpea [open circle; $\log (y)=1.67-0.82 \log (x)$; d.f.error $\left.=28 ; F=9.69 ; P=0.004 ; r^{2}=0.26\right)$ and mung bean [open triangle; $\log (y)=0.35-0.76 \log (x) ;$ d.f.error $=28 ; \quad F=7.84$; $P=0.009 ; r^{2}=0.22$ ).

seed were approximately twice as high as those reported by Dick \& Credland (1984), placing this strain closer to the scramble-type of competition outcome than expected. Takano et al. (2001) also found the Yemen strain to show a more intermediate type of competition outcome than would be likely based on earlier studies. The long maintenance of the Yemen strain in stock cultures of cowpea seeds may be favouring the partial loss of the peculiar traits (i.e. very high larval respiration rates, high per capita food consumption and nearly contest-type of competition outcome) originally reported on this strain. Future selection on lentils might reverse this trend.

The India and Yemen strains of $C$. maculatus showed higher rates of larval respiration than the remaining strains with wider differences recorded on mung bean rather than on cowpea. The respirometry data from the last measurement suggested a positive correlation with seed consumption. Based on the regressions between seed consumption and adult emergence per seed, high grain consumption per adult led to a decrease on adult emergence and favoured a contest-type of outcome of larval competition, as initially predicted. However, larval respiration rates did not appear to show any significant direct effect on adult emergence and are likely to have negligible influence on the competition outcome. Therefore, other factors such as number of eggs laid per seed are probably of major importance, together with per capita food consumption, in determining the competition outcome.

A differential feeding behaviour among strains appears to explain the competition outcome in strains of $C$. maculatus and this is supported by the respirometry results. Larvae from 'scramble' strains appear to show spatial segregation within the seed, feeding peripherally (Toquenaga, 1993). Such behaviour prevents interference among competing larvae, unless they are under high densities and/or advanced in their development, when interference behaviour may take place as suggested by Toquenaga (1993). By contrast, larvae from 'contest' strains show more uniform egg distribution favouring a time gap in development between the larvae from the first egg laid on the seed and the subsequent one (Thanthianga \& Mitchell, 1990). The older and therefore larger and dominant larva appears to burrow deeper towards the centre of the seed (Mitchell \& Thanthianga, 1990). This behaviour may benefit the dominant larva with a better food source favouring its already high rate of food consumption and respiration, creating a greater difference in body size between the dominant larva and the other younger competing ones, which are probably significantly smaller. The younger larvae probably remain confined in shallow burrows within the seed, but the high food consumption of larvae from these strains favours their interference with further development and the likely survival of the dominant larva. The expansion of respirometry and within-seed interference studies between larvae from the same and distinct strains will be helpful in testing this hypothesis.

\section{Acknowledgements}

We would like to express our gratitude to the U.K. Natural Resources Institute (formerly the Tropical Stored Products Centre), and Dr Peter Credland and Dr Frank Messina for providing the original stock strains of $C$. maculatus used in the present study. Financial support was provided by the CAPES Foundation from the Brazilian Ministry of Agriculture (RNCG).

\section{References}

Bellows, T.S. (1982) Analytical models for laboratory populations of Callosobruchus chinensis and Callosobruchus maculatus (Coleoptera, Bruchidae). Journal of Animal Ecology, 51, 263-287.

Berg, D.J. \& Mitchell, R. (1993) Associations of allozyme variation and behavior in the cowpea weevil (Callosobrucus maculatus). Entomologia Experimentalis et Applicata, 69, 215-220.

Chiu, Y. \& Messina, F.J. (1994) Effect of experience on host preference in Callosobruchus maculatus (Coleoptera: Bruchidae): variability among populations. Journal of Insect Behaviour, 7, 503-515.

Colegrave, N. (1994) Game theory models of competition in closed systems: asymmetries in fighting and competitive ability. Oikos, 71, 499-505.

Credland, P.F. (1986) Effect of host availability on reproductive performance in Callosobruchus maculatus (F.) (Coleoptera: Bruchidae). Journal of Stored Products Research, 22, 49-54.

Credland, P.F. \& Dick, K.M. (1987) Food consumption by larvae of three strains of Callosobruchus maculatus (Coleoptera: Bruchidae). Journal of Stored Products Research, 23, 31-40.

Credland, P.F., Dick, K.M. \& Wright, A.W. (1986) Relationships between larval density, adult size and egg production in cowpea seed beetle, Callosobruchus maculatus. Ecological Entomology, 11, 41-50.

Daniel, S.H. \& Smith, R.H. (1994) Functional anatomy of the egg pore in Callosobruchus maculatus: a trade-off between gas- 
exchange and protective functions? Physiological Entomology, 19, 30-38.

Dick, K.M. \& Credland, P.F. (1984) Egg production and development of three strains of Callosobruchus maculatus (F.) (Coleoptera: Bruchidae). Journal of Stored Products Research, 20, 221-227.

Dick, K.M. \& Credland, P.F. (1986) Variation in the response of Callosobruchus maculatus (F.) to a resistant variety of cowpea. Journal of Stored Products Research, 22, 43-48.

Fox, C.W. \& Czesak, M.E. (2000) Evolutionary ecology of progeny size in arthropods. Annual Review of Entomology, 45, 341-369.

Gilson, W.E. (1963) Differential respirometer of simplified and improved design. Science, 141, 531-532.

Guedes, R.N.C., Kambhampati, S. \& Dover, B.A. (1997) Allozyme variation among Brazilian and U.S. populations of Ryzopertha dominica resistant to insecticides. Entomologia Experimentalis et Applicata, 84, 49-57.

Horng, S. (1997) Larval competition and egg-laying decisions by the bean weevil, Callosobruchus maculatus. Animal Behaviour, 53, $1-12$.

Kawecki, T.J. (1995) Expression of genetic and environmental variation for life history characters on the usual and novel hosts in Callosobruchus maculatus (Coleoptera: Bruchidae). Heredity, 75, 70-76.

Kawecki, T.J. (1997) Habitat quality ranking depends on habitatindependent environmental factors: a model and results from Callosobruchus maculatus. Functional Ecology, 11, 247-254.

Lale, N.E.S. \& Vidal, S. (2001) Intraspecific and interspecific competition in Callosobruchus maculatus (F.) and Callosobruchus subinnotatus (Pic) on stored bambara groundnut, Vigna subterranean (L.) Verdcourt. Journal of Stored Products Research, 37, 329-338.

Messina, F.J. (1989) Genetic basis of variable oviposition behavior in Callosobruchus maculatus (Coleoptera: Bruchidae). Annals of the Entomological Society of America, 82, 792-796.

Messina, F.J., Gardner, S.L. \& Morse, G.E. (1991) Host discrimination by egg-laying seed beetles: causes of population differences. Animal Behaviour, 41, 773-780.

Mitchell, R. (1975) The evolution of oviposition tactics in the bean weevil, Callosobruchus maculatus (F.). Ecology, 56, 696-702.

Mitchell, R. \& Thanthianga, C. (1990) Are the oviposition traits of the South India strain of Callosobruchus maculatus maintained by natural selection? Entomologia Experimentalis et Applicata, 57, 143-150.

Møller, H., Smith, R.H. \& Sibly, R.M. (1989) Evolutionary demography of a bruchid beetle. II. Physiological manipulations. Functional Ecology, 3, 683-691.

Nicholson, A.J. (1954) An outline of the dynamics of animal populations. Australian Journal of Zoology, 2, 9-65.

Nylin, S. (2001) Life history perspectives on pest insects: what's the use? Austral Ecology, 26, 507-517.

Oigiangbe, N.O. \& Onigbinde, A.O. (1996) The association between some physico-chemical characteristics and susceptibility of cowpea (Vigna unguiculata (L.) walp) to Callosobruchus maculatus (F.). Journal of Stored Products Research, 32, 7-12.

SAS Institute (1989) SAS/STAT User's Guide, version 6. SAS Institute, Cary, NC, U.S.A.

Savalli, U.M., Czesak, M.E. \& Fox, C.W. (2000) Paternal investment in the seed beetle Callosobruchus maculatus (Coleoptera: Bruchidae): variation among populations. Annals of the Entomological Society of America, 93, 1173-1178.
Shade, R.E., Murdock, L.L. \& Kitch, L.W. (1999) Interactions between cowpea weevil (Coleoptera: Bruchidae) populations and Vigna (Leguminosae) species. Journal of Economic Entomology, 92, 740-745.

Smith, R.H. (1990) Adaptations of Callosobruchus species to competition. Bruchids and Legumes: Economics, Ecology and Coevolution (ed. by K. Fujii, A. M. R. Gatehouse, C. D. Johnson, R. Mitchell and Y. Yoshida), pp. 351-360. Kluwer, Dordrecht, The Netherlands.

Smith, R.H. (1991) Genetic and phenotypic aspects of life-history evolution in animals. Advances in Ecological Research, 21, 63-120.

Smith, R.H. \& Lessells, C.M. (1985) Oviposition, ovicide and larval competition in granivorous insects. Behavioural Ecology: Ecological Consequences of Adaptative Behaviour (ed. by R. M. Sibly and R. H. Smith), pp. 423-448. Blackwell Science, London.

Southgate, B.J. (1978) The importance of the Bruchidae as pests of grain legumes, their distribution and control. Pests of Grain Legumes: Ecology and Control (ed. by S. R. Singh, H. F. van Emden and T. A. Taylor), pp. 219-229. Academic, New York.

Southgate, B.J. (1979) Biology of the Bruchidae. Annual Review of Entomology, 24, 449-473.

Southgate, B.J., Howe, R.W. \& Brett, G.A. (1957) The specific status of Callosobruchus maculatus (F.) and C. analis (F.). Bulletin of Entomological Research, 48, 79-89.

Takano, M., Toquenaga, Y. \& Fujii, K. (2001) Polymorphism of competition types and its genetics in Callosobruchus maculatus (Coleoptera: Bruchidae). Population Ecology, 43, 265-273.

Tanaka, Y. (1990) Age specificity of inbreeding depression during a life cycle of Callosobruchus chinensis (Coleoptera: Bruchidae). Researches on Population Ecology, 32, 329-335.

Tatar, M. \& Carey, J.R. (1995) Nutrition mediates reproductive trade-offs with age-specific mortality in the beetle Callosobruchus maculatus. Ecology, 76, 2066-73.

Thanthianga, C. \& Mitchell, R. (1990) The fecundity and oviposition behavior of a South Indian strain of Callosobruchus maculates. Entomologia Experimentalis et Applicata, 57, 133-142.

Toquenaga, Y. (1990) The mechanism of contest and scramble competition in bruchid species. Bruchids and Legumes: Economics, Ecology and Coevolution (ed. by K. Fujii, A. M. R. Gatehouse, C. D. Johnson, R. Mitchell and Y. Yoshida), pp. 341-349. Kluwer, Dordrecht, The Netherlands.

Toquenaga, Y. (1993) Contest and scramble competitions in Callosobruchus maculatus (Coleoptera: Bruchidae) II. Larval competition and interference mechanisms. Researches on Population Ecology, 35, 57-68.

Tran, B.M.D. \& Credland, P.F. (1995) Consequences of inbreeding for the cowpea seed beetle, Callosobruchus maculatus (F.) (Coleoptera: Bruchidae). Biological Journal of the Linnean Society, 56, 483-503.

von Ende, C.N. (1993) Repeated-measures analysis: growth and other time-dependent measures. Design and Analysis of Ecological Experiments (ed. by S. M. Scheiner and J. Gurevitch), pp. 113-137. Chapman \& Hall, New York.

Wasserman, S.S. (1986) Genetic variation in adaptation to foodplants of the southern cowpea weevil, Callosobruchus maculatus: evolution of oviposition preference. Entomologia Experimentalis et Applicata, 42, 201-212.

Accepted 7 July 2003 